\title{
POLIMENE, María Paula. (coord.) Autoridades y prácticas judiciales en el Antiguo Régimen: problemas jurisdiccionales en el Río de la Plata, Córdoba, Tucumán, Cuyo y Chile. Rosario: Prohistoria Ediciones, 2011, 268 pp. ISSN: 978-987-1855-05-6
}

\author{
Ariel Mamani Cotonat ${ }^{\star}$
}

Durante mucho tiempo el estudio de una sociedad en su dimensión jurídica presentó ciertos escollos difíciles de sortear. Uno de ellos fue que muchas de las explicaciones ensayadas por los investigadores caían, sin más, en la configuración de un cuadro por demás reduccionista del funcionamiento de la justicia. Es así como una lectura exegética del aparato normativo, obviaba muchas veces examinar si aquello plasmado en la norma era cabalmente lo que se aplicaba a la realidad cotidiana. En otras palabras, lo que algunos estudiosos priorizaban, esto es, el estudio de la cultura jurídica a partir del análisis de la doctrina de ese momento histórico, podía llevar a conclusiones que no permitieran advertir la grieta existente entre forma y práctica.

En tiempos relativamente cercanos, nuevos enfoques teóricos y metodológicos han posibilitado estudiar desde otros ámbitos este importante campo, lo que ha llevado a dejar de pensar en una historia del derecho marcadamente autorreferencial para consolidar una historia (social) de la justicia. Hay que remarcar que en un principio, lo que había despertado el interés por los archivos judiciales no fue precisamente una apuesta por historizar la justicia. Este interés más bien provenía de una serie de inquietudes que buscaban asir características de aquellos grupos sociales considerados subalternos. No obstante, el estudio de la cultura jurídica y de las prácticas judiciales rebeló la estrecha relación entre éstas y el poder político, en especial para aquellas sociedades donde no operaba la división de poderes propia del republicanismo.

\footnotetext{
* - Universidad Nacional de Rosario - Argentina
} 
Esta ampliación del campo de estudio abrió un insospechado espacio de confluencia entre las funciones propias de la justicia y las funciones de gobierno, rompiendo una mirada no solo sesgada de los fenómenos históricos, sino fuertemente anclada en registros de análisis del aparato institucional que proyectaban hacia el pasado nociones actuales. Es por ello que muchos análisis del mundo colonial llevaron una fuerte marca de anacronismo, sin atender a las características propias de las sociedades de Antiguo Régimen. Así, se priorizó acentuar marcadamente los rasgos de discontinuidad entre la sistematización jurídica de la colonia y aquella resultante de la realidad revolucionaria, sin alcanzar a percibir las muchas formas que alcanzaron a sobrevivir una vez disuelto el orden colonial. Hay que destacar que esta manera de acercarse a la historia de la justicia ha impulsado a los investigadores, de la mano del paradigma jurisdiccionalista, a internarse en problemas poco transitados anteriormente, en especial aquellos relacionados a tecnologías de gobierno que buscaban organizar la extensión en territorio (HESPANHA, 1989). Una buena muestra de los avances descriptos es el volumen que aquí nos ocupa.

María Paula Polimene es una joven investigadora argentina que asumió la coordinación de la presente obra colectiva donde se reúnen una serie de trabajos presentados en las Primeras Jornadas de Historia Social de la Justicia, realizadas en 2010 en la Facultad de Humanidades y Artes de la Universidad Nacional de Rosario (Argentina). Los estudios que integran el presente volumen constituyen una aproximación al estudio de la cultura jurídico/judicial dentro de un enfoque específico y acentuadamente rico dentro del campo. El panorama brindado por los trabajos abarca desde el estudio de la administración de justicia (pasando obviamente por el análisis de pleitos judiciales y disputas jurisdiccionales) al proceso de institucionalización y equipamiento político a partir del funcionamiento de redes locales y/o supralocales. Es posible trazar un punto de fuga hacia donde se dirigen los artículos presentes en el libro: la configuración del poder en zonas periféricas de la Monarquía Hispánica, más allá de los particularismos propios de la localización a la que remite cada uno de los estudios.

Los artículos permiten visualizar uno de los avances esenciales en torno a la historia política y sus vínculos con la historia de la justicia al demostrar como el hecho de impartir justicia fue (principalmente) un acto de gobierno y no solo la aplicación pura de un conjunto de normativas. Como ha planteado Raúl Fradkin (2009), la cultura jurídica es un componente esencial para comprender la cultura política porque puede ilustrarnos sobre aquellas nociones de la sociedad, el poder y la autoridad que portaban los agentes.

Los autores presentes en el volumen expresan la importancia de introducirse en el estudio de la subjetividad de los agentes, por ello el enfoque microanalítico es preponderante, más no exclusivo. La conformación del poder político se analiza a partir de la reconstrucción de redes parentales y sociales con relevamientos minuciosos y constructivistas que posibilitan un acercamiento ajustado de las acciones e intereses de los involucrados. Esto también es esencial para comprender aspectos de la densificación de carácter institucional que derivaron en 
yuxtaposiciones jurisdiccionales y corporativas, rasgo sobresaliente de las formas de poder político del Antiguo Régimen.

También el enfoque microanalítico permite visualizar, como señala Elisa Caselli en la introducción de este volumen, un aspecto de la cultura jurídica poco observado hasta hace poco: aquellos rasgos de "infrajudicialidad", es decir una especie de ordenamiento jurídico paralelo, fuertemente anclado en la oralidad y de orden consuetudinario, lo que nos habla de una particular apropiación de la cultura letrada por parte de diversos sectores. Justamente, este interesantísimo estudio introductorio de Caselli trata sobre las prácticas judiciales en Castilla entre los siglos XV y $X V I$. Sus apreciaciones permiten trazar un claro panorama sobre el tema, lo que posibilita comprender las continuidades que en materia judicial se presentaron entre península y los espacios americanos de la Monarquía Hispánica.

Los diferentes artículos se organizaron siguiendo un orden cronológico. Inicia el desarrollo un trabajo de Carlos María Birocco sobre la investigación del Visitador Juan Joseph de Mutiloa al gobernador Manuel de Velasco ('“La pesquisa de Mutiloa en Buenos Aires'. Conformación de facciones y lucha por el poder en el cabildo porteño (1700-1715)"). Mutiloa fue enviado por Felipe $\mathrm{V}$ ante la denuncia de los capitulares hacia el gobernador, a quien acusaban de contrabando a gran escala. El estudio, a partir de un ajustado uso de las fuentes, dejar entrever la enmarañada red de facciones y vínculos familiares y políticos. En ellos aflora la diversificación de las inversiones económicas, en un espacio periférico de la Monarquía, que resultaba peligroso desentrañar. A su vez, el proceso judicial sirve al autor para analizar una red familiar en construcción, cuyo origen se da a partir de actividades económicas, pero observando su funcionamiento en el plano político.

Carolina González Undurraga trabaja sobre una extensa muestra del Archivo Nacional de Chile que corresponde al arco temporal que va entre 1700 y 1810 ('Para que mi justicia no perezca'. Esclavos y cultura judicial en Santiago de Chile, segunda mitad del siglo XVIII"). La autora bucea en las prácticas judiciales centrándose en los esclavos como grupo poblacional, profundizando en las relaciones que éstos establecían con las élites a partir de la justicia. De ese modo logra analizar la práctica de los representantes judiciales, encarnados en las figuras del escribano y del procurador de pobres, quienes fungían como mediadores entre demandantes (los esclavos) y la justicia.

Dos de los textos se ocupan del espacio entrerriano. Son los trabajos firmados por María Paula Polimene y por María Elena Barral. El primero de ellos, "El alcalde de la Hermandad del pago de Bajada entre 1784 y 1786", tiene como objetivo analizar los conflictos en relación a la designación del Alcalde de la Hermandad para el partido de la Bajada (hoy Paraná). Este cargo era por aquél entonces de capital importancia ya que Bajada no poseía cabildo, y por lo tanto estaba bajo la jurisdicción de Santa Fe. El trabajo ahonda en las disputas a partir de la acción de Tomás de Rocamora, quien al calor de las Reformas Borbónicas buscó fortalecer la posición del dominio hispánico en la costa occidental del río Uruguay. Esta zona fronteriza con indígenas y portugueses, fue segregada de la jurisdicción del Cabildo de Santa Fe en 1783 a partir de la fundación de una red de ciudades sobre asentamientos previos (Gualeguay, Gualeguaychú y Concepción del Uruguay), 
forjando una nueva dinámica al desencadenarse una puja jurisdiccional entre los capitulares santafesinos y los comandantes militares del oriente entrerriano. El artículo pretende un acercamiento al proceso de equipamiento político de este espacio donde se pone en juego la presencia de intereses particulares y grupales del ámbito capitular, en colisión con proyectos políticos supralocales.

En un mismo sentido "Las parroquias del suroriente entrerriano a fines del siglo XVIII", de María Elena Barral, trabaja precisamente sobre el proceso de territorialización impulsado por Tomás de Rocamora, destacando que dicha "(...) institucionalización no operaba en el vacío y en consecuencia se topó con grupos de poder a nivel local que no estaban dispuestos a ceder sin más a la expropiación de las formas de ejercicio de la autoridad." (p. 94). Concentrándose en Gualeguay, la autora logra desplegar la rica paleta de representaciones diversas frente al proceso de institucionalización borbónica. Barral examina como se fueron resolviendo las disputas jurisdiccionales, centrándose en querellas eclesiásticas y religiosas, que son expresiones de la reacción ante la avanzada borbónica en un espacio poco territorializado por la corona pero con una importante cultura jurídica y política que mostraba múltiples maneras de ejercer y fundamentar el poder.

Sigue un artículo de Romina Zamora sobre la administración de justicia en San Miguel de Tucumán. Allí analiza como a fines del siglo XVIII el crecimiento de la población libre alteró el orden tradicional, y como se utilizaron mecanismos de disciplinamiento, dentro de un orden jurídico que no se asentaba en la aplicación del Derecho positivo sino en el intento de desactivar conflictos a partir del restablecimiento del "orden social", evaluando penas a partir de criterios tales como la utilidad o el perjuicio para la comunidad. Por ello la autora destaca como los capitulares tucumanos ejercían el regimiento de la ciudad con "procedimientos y razones domésticas" trasgrediendo criterios legalistas y administrativos, característica que se acentuaba por no ser San Miguel de Tucumán sede de Real Audiencia ni Intendencia.

El reformismo borbónico es un tema que está lejos de haberse aclarado del todo. Múltiples interpretaciones se ciernen sobre este tema y aún queda mucho por investigar. Algunos de los trabajos del presente volumen aportan datos que podrán ser incluíos en futuras síntesis explicativas, especialmente en lo referido a la construcción institucional derivada de las reformas materializadas en la densificación de las redes institucionales. Quizás el artículo de María Elisabeth Rustán plantea el tema del reformismo de forma más explícita al adherir a la idea de que los cambios impulsados desafiaron a las estructuras y los privilegios corporativos en pos de un fortalecimiento de la monarquía. De esta manera Rustán analiza las transformaciones del Corregimiento de Cuyo, en tanto unidad administrativa que pasó de la Capitanía General de Chile a la jurisdicción del Río de la Plata. A su vez, la autora trabaja dos casos de la villa de La Carlota hacia 1790, donde la militarización puesta en práctica por el reformismo carolino significó la incorporación de sectores subalternos a la vida institucional y política. 
Dos son los artículos dedicados específicamente a Mendoza: "Repartir sin pasión ni afición”. Prácticas jurídicas en torno al uso del agua en Mendoza virreinal" de Inés Sanjurjo de Driollet; y "Trayectorias judiciales, movilidad social y vida pública. Los jueces inferiores en Mendoza, 17701810", escrito por Eugenia Molina. El primero de ellos analiza los conflictos originados a partir del acceso, uso y control del agua, recurso imprescindible para esta zona. Un trabajo minucioso con las fuentes documentales le permite a la autora exponer las estrategias y manipulaciones de ciertos grupos para evitar las regulaciones y así cometer abusos en el uso de recursos hídricos (acequias, canales, tomas y cursos de agua). Si bien el gobierno de la ciudad pretendía lograr un reparto equitativo, las repetidas disposiciones relacionadas al buen uso no pudieron evitar controversias y abusos. Por ello la disputa en torno a la justicia de aguas es el espacio de trabajo de Sanjurjo, valiéndose de expedientes referidos a pleitos mayormente presentados ante alcaldes ordinarios, donde pueden visualizarse en algunos casos, la colisión entre intereses privados y el bien general. Se destaca además, como políticas impulsadas por la Corona, como es el caso de la minería, provocaron la imposición de medidas que lesionaron claramente el bien común.

El estudio firmado por Molina, tiene como objetivo estudiar el cuerpo de jueces menores de Mendoza entre 1770 y 1810 . A partir de 373 expedientes brinda un cuidado abordaje prosopográfico de muchos de los personajes que componen el elenco judicial. La autora demuestra con el estudio del elenco de jueces menores que, si bien los grupos dirigentes relacionados a la prosapia de los fundadores y encomenderos, siguieron controlando los cargos más importantes de gobierno, fueron permeables a cierta apertura a partir de facilitar la llegada de otros sectores a la administración de justicia, a través de jueces pedáneos. Así la autora logra marcar las diferencias en los cargos de la justicia menor a partir de los perfiles y jurisdicciones establecidos entre los Alcalde de la Hermandad y los otros tipos de alcaldías.

Hace tiempo que se ha demostrado que historiar sobre la justicia debe partir de una periodización temporal diferente de la que suele utilizarse en otras áreas. Esto no quiere decir que deban desconocerse los cortes propuestos por gran parte de la historiografía sino que debe prestarse atención a los diferentes cadencias que marcan continuidades y rupturas de otro orden que las de tipo político o económico. Es por ello que se incluyen en este libro trabajos que se topan con la crisis de disolución del vínculo colonial, demostrando que muchos elementos propios del Antiguo Régimen permanecieron por un tiempo a pesar de la ruptura. En este sentido marchan los dos últimos artículos del libro.

Irina Polastrelli titula su trabajo '“Faltando a los Deberes del Buen Vasallo'. El juicio a los acusados de intentar independizar el Río de La Plata, 1809-1810". Allí trabaja un proceso judicial muy interesante porque se da "a caballo" del orden colonial y del nuevo ordenamiento surgido de la destitución del virrey Cisneros y el establecimiento de una junta en mayo de 1810. Este panorama fue particularmente conflictivo para el espacio rioplatense porque encarnaba la yuxtaposición de dos crisis. Por un lado la crisis de orden local desencadenada por las invasiones inglesas de 1806 y 1807, que habían modificado sustancialmente el cuadro de situación en el virreinato. Por el otro, la 
vacatio regis provocada por los sucesos de Bayona. El artículo estudia el proceso judicial por el cual se acusó a Martín de Álzaga, a Felipe de Sentenach y a Miguel de Esquiaga, de intentar "independizar" al Río de la Plata. La autora primero analiza el proceso judicial en sí, mientras que en un segundo momento, a partir de la critica conceptual, profundiza en lo argumentos esgrimidos en la acusación revisando el lenguaje utilizado para criminalizar a los imputados.

El último artículo del volumen pertenece a la pluma de Darío Barriera, figura que representa hoy día toda una autoridad e el campo de la historia social de la justicia por la cantidad y densidad de trabajos encarados sobre esta temática. Su extenso escrito se ocupa de la dura querella desatada entre don Isidro Noguera, Alcalde de la Hermandad del Pago de los Arroyos, y el cura Julián Navarro. Otros personajes se suman a la trama de provocaciones y pugnas, lo que permite vislumbrar aspectos importantes de la intersección entre las autoridades y otros agentes. Esto posibilita pensar a la cultura jurídica y las formas de equipamiento del territorio en tiempos de sensibles cambios políticos en el Río de la Plata (1810-1811). El texto se articula en tres segmentos bien diferenciados. En el primero de ellos se deja constancia del pleito en sí y del escenario en donde éste se desarrolló. La segunda parte del trabajo apunta una serie de datos importantes sobre los agentes implicados, cuestión cardinal para comprender la compleja configuración donde se desarrolla la trama relacional de los involucrados. El tercer apartado reconstruye y analiza muchas de nociones que portaban los agentes en relación a la autoridad y al poder en un escenario por demás de complejo. El texto de Barriera es enormemente rico. Compacto en su estructura, presenta frondosa información y despliega un revelador número de significaciones. El texto se destaca por la claridad conceptual y el ajustadísimo tratamiento metodológico. Podría decirse que el trabajo opera casi como un modelo de enfoque microanalítico, donde el análisis relacional de los agentes, y las circunstancias derivadas de sus acciones, son trabajadas por el autor con enorme sapiencia, creatividad e inteligencia. Hay un excepcional manejo de las fuentes documentales, destacándose el procedimiento heurístico. Da la sensación de que cada documento ha sido "exprimido" al máximo, demostrando un trabajo meticuloso y sistemático al que nos tiene acostumbrado el autor.

En definitiva, el libro es un eslabón más en la prolífica producción de la historiografía argentina que permite comprender la constitución del poder político y la dinámica jurídico-política en espacios de frontera. Los trabajos reunidos en este volumen representan una forma de historiar a la justicia que ha llevado a la multiplicación de estudios a partir de los archivos locales. Lo que fue durante un tiempo una de las tantas modas historiográficas, hoy está dando sus frutos. Es por ello que el libro es un significativo aporte para lograr visualizar de forma más completa la acción de los propios agentes, sus relaciones políticas y sociales, y así adentrarse en las ideas que poseían sobre el poder, el gobierno y la justicia.

\section{Referências}




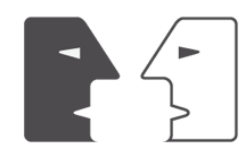

ANTITESES

FRADKIN, Raúl. "Cultura jurídica y cultura política: la población rural de Buenos Aires en una época de transición (1780-1830)". En: FRADKIN, Raúl La ley es tela de araña. Ley, justicia y sociedad rural en Buenos Aires, 1780-1830, Buenos Aires, Prometeo, 2009, pp. 159-186.

HESPANHA, Antonio Manuel. Vísperas del Leviatán. Instituciones y poder político. Portugal Siglo XVII, Madrid: Taurus Ediciones, 1989.

Recebido em 20.04.2014 - aprovado em 17.11.2015. 